\title{
SCIDiC
}

\author{
International Journal of Dentistry and Oral Science (IJDOS) \\ ISSN: 2377-8075
}

\section{Retrospective Study Of Dental Implants Survival Rate In Postmenopausal Women With Osteoporosis}

\author{
Research Article
}

Wasim Alsaadi ${ }^{*}$, Ali AbouSulaiman², Mohammad Monzer AlSabbagh ${ }^{3}$

${ }^{1}$ MSc, Department of Periodontology, Damascus University, Syria.

${ }^{2} \mathrm{PhD}$, Department of Periodontology, Damascus University, Syria.

${ }^{3} \mathrm{PhD}$, Department of Periodontology, Damascus University, Syria

Abstract

Background: The impact of osteoporosis on implant treatment remains debatable among the science community, with the goal to evaluate long-term implant success rate in patients with osteoporosis.

Methods: Patients who underwent dental implant treatment at least 4 years ago were divided into two groups [Test (osteoporosis/osteopenia) Group and Control Group] according to bone mineral density (BMD) measurements.

Results: A total of 52 patients with a mean age of $59.51 \pm 5.66$ years (Test Group; 26 patients, mean age: 60.61; Control Group; 26 patients, mean age: 58.42) were included in the study. Implant survival rates were $96.2 \%$ and $100 \%$ with a mean follow-up $60.84 \pm 22.13$ and $60.07 \pm 20.93$ months in Test and Control Groups, respectively $(\mathrm{P}>0.05)$. While peri-implant PI (plaque index) and PD (probing depth) were not different between the groups, BoP (bleeding on probing) was significantly higher in Test Group $(\mathrm{P}=0,026)$. Although Cristal bone label $(\mathrm{CBL})$ in Test Group was higher than Control Group (0.82 \pm $0,63 \mathrm{~mm}$ and $0.44 \pm 0,33 \mathrm{~mm}$ respectively), the difference was not found statistically significant $(\mathrm{P}=0.069)$.

Conclusions: The findings recommend that dental implant therapy is a reliable treatment method for those patients to improve the quality of life by increasing function and aesthetics.

Keywords: Osteoporosis; Implants; Postmenopausal Women.

Abbreviations: PI: Plaque Index; PD: Probing Depth; BoP: Bleeding On Probing; BMD: Bone Mineral Density; MBL: Marginal Bone Loss.

\section{Introduction}

Osteoporosis is a systemic skeletal disease characterized by reduced bone strength that predisposes to an increased risk of fractures [28]. It is a very common disease which affects an estimated 300 million people worldwide [21, 31]. It is most common in females and its incidence increases with age $[17,37]$. It is usually accompanied with the destruction of bone microarchitecture with reduced bone mass and strength and increased fragility [40]. The resistance reflects the amount of bone density and bone quality. Bone density is determined by the maximum value of bone mass (measured in grams per $\mathrm{cm}^{2}$ ) and the magnitude of their loss. The diagnosis of osteoporosis was established based on the classical values of bone mineral density (BMD) achieved in the bone den- sitometry. This method call dual x ray absorptiometry for Lumbar vertebrae (L1, L2, L3, L4) After that, he took the average of the four paragraphs. The osteoporosis was considered when the Tscore of less than $-2.5 \mathrm{SD}$ (the $\mathrm{T}$ number of standard deviations that a subject deviate from the average BMD of a population group of healthy young women [8] Figure(1). This classification followed by the World Health Organization WHO.

Currently the BMD is only considered a risk factor that must be assessed in the context of age, sex, smoking, body weight, family history and / or personal fracture, etc $[11,27]$.

Management of osteoporosis patient by using medication (bisphonates(Alendronate-Risendronate), Glucose calcium 500 $-1000 \mathrm{mg}$ and vit D3 600 units) [41].

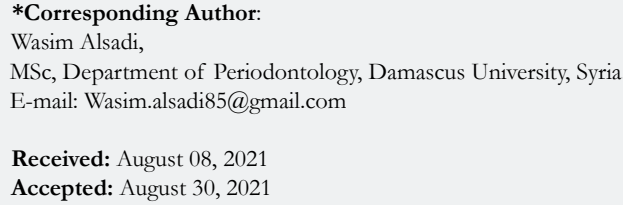

Citation: Wasim Alsaadi, Ali AbouSulaiman, Mohammad Monzer AlSabbagh. Retrospective Study Of Dental Implants Survival Rate In Postmenopausal Women With Osteoporosis. Int J Dentistry Oral Sci. 2021;8(9):4259-4266. doi: doi: http://dx.doi.org/10.19070/2377-8075-21000868

Copyright: Wasim Alsadi 2021 . This is an open-access article distributed under the terms of the Creative Commons Attribution License, which permits unrestricted use, distribution and reproduction in any medium, provided the original author and source are credited. 


\section{Methods}

Female Patients, 50 years of age or older, who had been rehabilitated with dental implants placed during 2015. Patients who agreed to sign informed consent and were willing to attend the study were given a control appointment. The study was conducted according to the principles of the Helsinki Declaration of 1975, as revised in 2013. All appropriate patient consent forms. In the form the patient(s) has/have given her/their consent for her/ their images and other clinical information to be reported in the journal. The patients understand that their names and initials will not be published and due efforts will be made to conceal their identity, but anonymity cannot be guaranteed. The patients were taken from the Al-Assad University Hospital, Damascus University, and the research was conducted at Damascus University as a master's research and Master's decision number 2733.

Initially, 280 women with minimum one dental implant being in function for at least 3 years were called and asked to bring their (DXA) measurements. Information about their age, osteoporotic diagnosis based on T-score, duration of follow-up, smoking habits, systemic conditions, medication, data concerning implant insertion, and prosthetic rehabilitation and any implant failures were provided using their medical and dental records. Subjects unaware of their bone status, because of not having bone mineral density (BMD) assessment, were excluded from the study. Patients who had systemic diseases that may affect implant success such as uncontrolled diabetes, heavy parafunctions (e.g., bruxism), with a history of bone augmentation and/or sinus lift and smoking habit were also excluded. The patients' osteoporotic status was determined according to T-scores based on The World Health Organization (WHO) criteria. Subjects meeting all of the inclusion and neither of the exclusion criteria were divided into two study groups regarding each subject's lowest T-score.

\section{Inclusion Criteria}

1. Being postmenopausal woman over 50 years of age with BMD measurements,

2. Having been rehabilitated by dental implants in 2015 or before,

3. Using medication related of osteoporosis (bisphonates and calcium) regularly.

4. Having fixed prosthesis over implants only one crown or bridge, exposed to balanced occlusal forces.

5. Not having a history of periodontal $\backslash$ prei -implant disease.

6. Not having any systemic diseases.

7. Not smoking,

8. Being volunteer to participate in the study.

9. No taking any hormonal drugs

10. Not having sever osteoporosis

11. Not having osteonecrosis of the jaws

\section{Exclusion Criteria}

1. Lack of BMD measurements,

2. Having been rehabilitated by dental implants after 2015,

3. Presence of systemic diseases that may affect implant success such as uncontrolled diabetes.

4. Smoking,

5. History of bone grafting and/or sinus lift,

6. Severe parafunctional habits such as bruxism.

7. Unregularly or not medication osteoporosis

8. Having over denture or Exaggerated cantilever prothesis.

9. Lack oral hygiene

While Control Group included subjects with a T-score $\geq-1$, Test Group (osteoporosis/osteopenia group) included subjects with a T-score $<-1$. DXA were adopted for a period of no more than 6 months

During clinical examination, pain , movement, history of swell-

Table 1.

\begin{tabular}{|c|c|}
\hline Diagnostic category & Osteoporosis definition \\
\hline Normal & T-score $\geq-1$ \\
\hline Osteopenia & $-2.6<$ T-score $<-1$ \\
\hline Osteoporosis & T-score $\leq-2.6$ \\
\hline Severe $\backslash$ established osteoporosis & T-score $\leq-2.6$ and the presence of one or more fragility fractures \\
\hline
\end{tabular}

Figure 1. Dual x Ray Absorptiometry measurement (DXA).

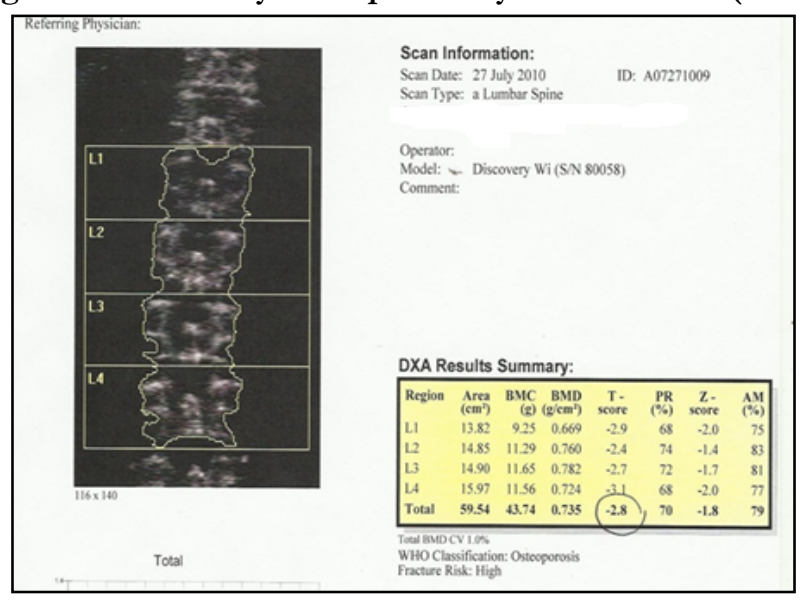


ing, presence of plaque (plaque index [PI]) and the status of the soft tissue around the implant (probing depth [PD] and bleeding on probing $[\mathrm{BoP}]$ ) were checked by a single calibrated examiner (V.E.T.). Probing of the peri-implant pocket was performed at six sites per implant (mesiobuccal, buccal, distobuccal, mesiolingual/ mesiopalatal, lingual/palatal and distolingual/distopalatal), and the mean value was used in calculations. The location of the implants, date of insertion and functional loading, and any implant failures were also recorded. If the implants were stable and in function without mobility, they are believed to survive, having no pain or suppuration with the lack of peri-implant radiolucency. However, implant survival just means that it has not been lost but not informs about its situation and the implant success. The amount of CBL gives more information about the long-term outcomes of implants. Health Scale For Dental Implants was taken To determine the survival or failure of implants [42].

Standardized periapical were taken with a digital X-ray machine and marginal bone levels were assessed using image analysis software (Planmeca, Romexis 3.5.1.R). A researcher blinded to the BMD status of the patient (V.E.T.) took the measurements on radiographs and known implant lengths were used for calibration. Marginal bone levels (MBL) were measured as the linear distance between the reference point, implant-abutment junction, and the most coronal point of bone-to-implant contact, both mesially and distally. The average of mesial and distal measurements was calculated to determine a single value for each implant. Parallelly technique Digital periapical radiograph taken at the time of implant insertion were regarded as baseline and MBL was calculated as the difference between the Cristal bone level at baseline and the follow-up appointment. For every patient in the study, all of the measurements were averaged into one. Duration of follow-up was calculated from the date of implant insertion to the date of recall visit. Finally, the study was completed with a total of 52 patients with 244 implants.

\section{Statistical Analysis}

Sample size was calculated at the beginning of the study $(\alpha=0$. $5,1-\beta$ (power $)=0.8)$. It was estimated that at least 21 volunteers for each group would be enough to find a difference of $0.34 \mathrm{~mm}$ amount of mean MBL between the groups. The data given were analyzed using SPSS. A descriptive analysis was performed using standard deviation (SD) and median with $96 \%$ confidence inter- val (CI). Only ages of the subjects showed normal distribution and were presented as means and SDs of means and compared between the groups by using Independent-samples t test. Analysis of other parameters (T-score, number of implants, follow-up period, PI, PD, BoP and amount of MBL) did not show normal distributions. Therefore, the data for those parameters were presented as means and SDs of means, and median values with minimum/maximum. The differences between the groups were analyzed using Mann-Whitney U test. Fisher's Exact Chi-square Test was used for comparing implant survival rates between the groups on a patient basis. A P value $<0.06$ was considered statistically significant.

\section{Results}

A total of 52 women with 245 dental implants who were approved by the inclusion criteria were included in the study. Patient demographics are listed. While Test Group included 27 subjects with a mean T-score of $-2,54 \pm 0,55$; Control Group included 26 subjects whose mean T-score was $-0,95 \pm 1,70$ being significantly lower than Test Group ( $\mathrm{P}=0,001)$. The mean age of the subjects in Test and Control Groups were determined as $60.62 \pm 5.70$ and $58.40 \pm 5.20$, respectively and there was no statistically significant difference between the groups.

One hundred and twenty implants were placed in 27 osteoporosis/osteopenia subjects and 124 were placed in 26 control subjects; with an average of $4.61 \pm 3.29$ and $4.76 \pm 2.14$ implants per patient.

The mean follow-up period was $60.80 \pm 22.16$ and $60.07 \pm 20.93$ months in Test and Control Groups respectively. All of the implants were followed for at least 36 months. No significant differences were seen between the groups in terms of implant related factors. Figure (2).

Data regarding peri-implant soft tissue status and MBL are summarized in the table stated above.

There were no significant differences for PI, PD values, and the amount of MBL between the groups. Although the mean MBL in Test Group ( $0.81 \pm 0,64 \mathrm{~mm})$ was higher than Control Group $(0.45 \pm 0,35 \mathrm{~mm})$, the difference was not found statistically significant $(\mathrm{P}=0.069)$. Only BoP percentage of Test Group was sig-

Figure 2.

\begin{tabular}{|c|c|}
\hline $\begin{array}{l}\text { Implant qualiny Scale } \\
\text { Group }\end{array}$ & Clinical Conditions \\
\hline I. Success (optimum health) & $\begin{array}{l}\text { a) No pain or tenderness upon function } \\
\text { b) } 0 \text { mobility } \\
\text { c) }<2 \mathrm{~mm} \text { radiographic bone loss from initia } \\
\text { surgery } \\
\text { d) No exudates history }\end{array}$ \\
\hline II. Satisfactory survival & $\begin{array}{l}\text { a) No pain on function } \\
\text { b) } 0 \text { mobility } \\
\text { c) } 2-4 \text { mm radiographic bone loss } \\
\text { d) No exudates history }\end{array}$ \\
\hline III. Compromised survival & $\begin{array}{l}\text { a) May have sensitivity on function } \\
\text { b) No mobility } \\
\text { c) Radiographic bone loss }>4 \mathrm{~mm} \text { (less thar } \\
1 / 2 \text { of implant body) } \\
\text { d) Probing depth }>7 \mathrm{~mm} \\
\text { e) May have exudates history }\end{array}$ \\
\hline N. Failure (clinical or absolute failure) & $\begin{array}{l}\text { Any of following: } \\
\text { a) Pain on function } \\
\text { b) Mobility } \\
\text { c) Radiographic bone loss }>1 / 2 \text { length of } \\
\text { implant } \\
\text { d) Uncontrolled exudate } \\
\text { e) No longer in mouth }\end{array}$ \\
\hline
\end{tabular}


Table 2.

\begin{tabular}{|c|c|c|c|c|}
\hline & Total & Test group & Control group & P \\
\hline Number of individuals (n) & 52 & 27 & 26 & \\
\hline Age in years (mean \pm SD) & 59,51 & 60,61 & 57,42 & 0,166 \\
\hline T-score & & & & \\
\hline Mean \pm SD & $-0,97$ & $-2,55$ & 0,58 & 0,001 \\
\hline Median & & $-2,60$ & 0,90 & \\
\hline Min/Max & $-3,40 / 1,60$ & $-3,40 /-1,21$ & $-0,80 / 1,60$ & \\
\hline
\end{tabular}

Table 3.

\begin{tabular}{|c|c|c|c|}
\hline & Test group & Control group & P (P>0,05) \\
\hline Number of participants & 27 & 26 & \\
\hline Total number of implants & 120 & 124 & 0,326 \\
\hline Implant number per patient & 4,62 & 4,75 & \\
\hline Implant number per location & & & \\
\hline Anterior mandible & 22 & 52 & \\
\hline Posterior mandible & 51 & 14 & \\
\hline Anterior maxilla & 13 & 47 & 0,935 \\
\hline Posterior maxilla & 36 & $60,07 \pm 20,93$ & \\
\hline Observation period (months) & $60,80 \pm 22,16$ & & \\
\hline
\end{tabular}

Table 4.

\begin{tabular}{|c|c|c|c|}
\hline \multicolumn{4}{|c|}{ Peri-implant soft tissue status and marginal bone level changes } \\
\hline Peri-implant parameters & Test group & Control group & P \\
\hline PI & & & 0,496 \\
\hline Mean \pm SD & $1,70 \pm 0,81$ & $1,60 \pm 0.80$ & \\
\hline Median (Min-Max) & $2,00(0.00-3,0)$ & $1,63(0,00-3,00)$ & 0.906 \\
\hline PD (mm) & & & \\
\hline Mean \pm SD & $2,72 \pm 0,74$ & $2,68 \pm 0,65$ & 0.025 \\
\hline Median (Min-Max) & $2,90(1,00-4,14)$ & $2,79(1,25-4,13)$ & \\
\hline BOP (\%of sites) & & & $54,93 \pm 30,08$ \\
\hline Mean \pm SD & $70,58 \pm 35,05$ & $58,33(0-100)$ & \\
\hline Median (Min-Max) & $78,10(0-100)$ & & \\
\hline MBL (mm) & & $0.45 \pm 0,35$ & \\
\hline Mean \pm SD & $0.81 \pm 0,64$ & $0,38(0,07-1,32)$ & \\
\hline Median (Min-Max) & $0,81(0,00-2,08)$ & & \\
\hline
\end{tabular}

Table 5.

\begin{tabular}{|c|c|c|c|c|}
\hline & Total & Test group & Control group & P \\
\hline Number of implants/ patients & $244 / 52$ & $120 / 27$ & $124 / 26$ & 0,326 \\
\hline Number of implants lost & 1 & 1 & 0 & \\
\hline Survival rate & $98,2 \%$ & $96,3 \%$ & $100 \%$ & 0,313 \\
\hline
\end{tabular}

Figure 3. A periapical radiograph showing the resorption around the implant.

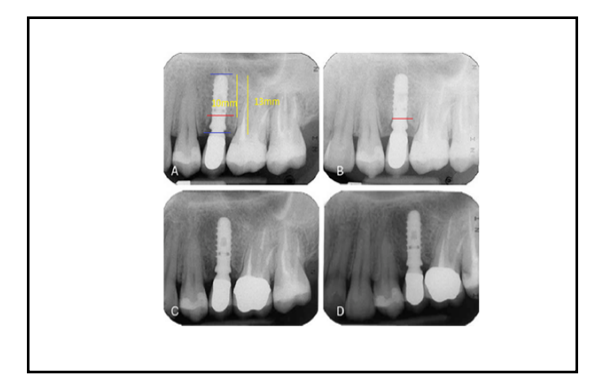


nificantly higher than Control Group (70.58 \pm 35.05\% and 54.93 $\pm 30.08 \%$ respectively).

The only implant failure was detected in a patient in Test Group resulting an overall implant survival rate of $98.1 \%$ on subject level at the 5-year follow-up. The implant supported a mandibular overdenture and was inserted in the region of the left mandibular canine. It was lost 2 years after implant placement and a new implant was successfully inserted 3 months after failure and no additional complication was encountered. No statistically significant difference was observed between the groups regarding the implant survival rates $(96.3 \%$ versus $100 \%$ in Test and Control Groups, respectively; P = 0,313). Implant Survival Rate

\section{Discussion}

Since the average life expectancy is progressively increasing, patients need more dental implants. Long-term success and survival rates of Osseo integrated implants have been reported in a number of studies but it is controversial regarding the patients with Osteoporosis [18]. Many studies have suggested a possible relationship between periodontal disease and Osteoporosis; Figure (3) $[38,4,29]$. Although knowledge about the correlation between skeletal and mandibular/maxillary BMD in osteoporotic patients is scarce and an association between implant failure and osteoporosis has not been proved, osteoporosis has been proposed as a risk factor for implant failure $[16,3]$. It has been considered to reduce the rate of bone-to-implant contact and the bone support because of decreased cancellous bone volume [6, $25]$. On the other hand, there are studies reporting contrary results [14]. As a better understanding was required, this study was conducted to evaluate the effects of osteoporosis/osteopenia on long-term survival rates of dental implants and MBL in PW. In this retrospective study, after a mean follow-up of $60.50 \pm 21.30$ months, $2,0 \%$ of all implants placed and $4,2 \%$ of implants in Test Group failed. MBL was $0.85 \pm 0.69 \mathrm{~mm}$ and $0.47 \pm 0,35 \mathrm{~mm}$ for Test and Control Groups respectively with no significant differences between the groups.

Osteoporosis has been defined as a decrease in bone mass and density and an increased risk of fracture [8]. Type 1 osteoporosis generally appears in PW aged over 50 as a result of decrease in estrogen levels and causes women to be susceptible to fracture [9]. WHO has defined diagnostic criteria for osteoporosis based on BMD measurements determined by DXA $[15,8,34]$. It is diagnosed as osteoporosis if the T-score, defined according to the BMD measurements at the hip or lumbar spine, is less than or equal to 2.5 standard deviations (SDs) below the mean of a young-adult reference population ( $\mathrm{T}$-score $\leq 2.5$ ). When the $\mathrm{T}$ score is between -2.5 and -1 , then a diagnosis of osteopenia is made [Table 1]. Although DXA imaging has been proposed as the "gold standard" for diagnosis of osteoporosis, WHO definition has been criticized since it does not regard male T-scores and the T-scores of the skeletal bones in other parts of the body [7]. So updated guidelines recommend the use of BMD at both proximal femur and lumbar spine and choosing the lower one. While determining the osteoporotic status of patients, we used the lowest T-scores either of femur or lumbar spine in order to increase the susceptibility of WHO definition [20].

According to the American Academy of Periodontology, Osseo integration is defined as a direct structural and functional contact without having a fibrous tissue between living bone tissue and an implant surface under loading [19]. Given that the amount and quality of bone at the implant recipient site is very important for a successful osseointegration, the effects of osteoporosis on implant success has been investigated in many studies up to now. In many studies osteoporosis was found to be significantly associated with early but not late implant failures $[16,5,33]$. TrullenqueEriksson et al. assessed long-term outcomes of Osseo integrated dental implants and factors that may have influenced implant survival and MBL. They concluded that patients with osteopenia/ osteoporosis presented implant failure more frequently. In this study 105 patients with 342 dental implants were included in the study but how many of them were diagnosed as osteopenia or osteoporosis is unknown so the power of the study is questionable [1]. A recently conducted systematic review with meta-analysis presented that while there was no difference in implant survival rate between patients with and without osteoporosis, MBL around implants revealed a significant difference [16].

On the other hand, there are studies reporting opposite results. In a review on osteoporosis, the evidence for an association between osteoporosis and implant failure was reported to be weak [3]. In another review, it was reported that osteoporosis has been shown to influence osseointegration in preclinical models but not in clinical studies $[22,35]$. Holahan et al., demonstrated that osteoporotic status had not affected the survival rate of implants and osteoporosis was not regarded as a contraindication for implant therapy [18]. In another study it was suggested that osteoporotic status and systemic BMD were not associated with local jawbone quality [2]. Dvorak et al. assessed the success rate of dental implants in PW and concluded that PO was not a risk factor for implant loss and periimplantitis [12]. It was also shown that reduced skeletal BMD did not affect survival rate of implants supporting mandibular overdentures [10]. The high survival rate found in this study was attributed to exclusion of patients with risk factors such as smoking, uncontrolled diabetes and alveolar deficiencies as in our study. In the prospective study performed by Temmerman et al., [39] PW with osteoporosis/osteopenia were followed at 6 months and 1 year after functional loading. While the cumulative survival rates were not significantly different between the groups, there was a significant difference in MBL, being higher in osteoporosis/osteopenia group, after 1 year of functional loading. All of these results, except Temmerman's findings, are consistent with the results found in our study. Although amount of MBL in Test Group was higher than control subjects in our study, it was not statistically significant.

The effects of osteoporosis on implant implantation and on the osseointegrated implants should be considered as two separate topics. In this study, we examined the long-term implant success of dental implants inserted at least 3 years ago in PW retrospectively. Therefore, we both evaluated the effects of osteoporosis/ osteopenia on implant implantation and on the osseointegrated implants. Besides date of insertion and functional loading, any implant failures were also recorded. When regarding the implant survival rates, the only failed implant was lost 2 years after implant placement so it can be concluded that osteoporotic status did not affect implant implantation or, in other words, osseointegration. On the other hand, although an implant was lost in Test Group resulting an overall implant survival rate of $98.1 \%$ on subject level, no statistically significant difference was observed between the 
groups. It can also be concluded that osteoporotic status did not affect osseointegrated implants too.

Success of dental implants is generally described by implant survival but progressing MBL could risk the long-term survival. A surviving implant does not absolutely mean the maintenance of well-being, only shows that it has not been lost. Implant success criteria, regarding MBL and other parameters, are considered as the gold standard for implant success [32]. To evaluate the longterm prognosis of an implant, it is mandatory to calculate the amount of MBL for a follow-up period. So, in our study, along with survival rates, we evaluated the amounts of MBL which was less than the amount defined by Albrektsson et al.; figure (4) as implant success criteria [30].

Currently approved medications for the treatment of PO are calcium, vitamin D, bisphosphonates (BPs), hormone replacement therapy, selective estrogen receptor modulators, calcitonin, parathyroid hormone, denosumab, and strontium ranelate. Oral BPs are commonly prescribed pharmacological agents in the treatment of osteoporosis. Osteonecrosis of the jaw (ONJ) has been reported due to oral surgery, including dental implants in patients using BPs in many studies [24]. The likelihood of ONJ may vary depending on the dose, duration, route of administration and the type of BP. Oral BP usage for less than 5 years has been reported to be reliable for dental procedures, particularly for dental implants. It was stated that especially intravenously administered BPs should be considered as a contraindication for dental implant therapy [23]. In the literature, it was reported that more than $90 \%$ of the ONJ cases had been seen in patients receiving intravenous BP, while cases in patients using oral BP were scarce. The American Association of Oral and Maxillofacial Surgeons has suggested to stop usage of BPs 3 months before and after oral surgery in patients using BPs for more than 3 years [13]. Only a few of the subjects, six of 26 patients in Test Group (23.07\%) in the present study were treated with BPs. Three of them have been rehabilitated with implants after they had given up using the drug. Two of the subjects started BP therapy after implant installation and only one patient was on BP treatment during surgery. All of the subjects using BP were orally administered. Six of the remaining patients were treated with calcium supplementation, one with vitamin $\mathrm{D}$ and calcium and one with calcium, vitamin $\mathrm{D}$ and denosumab. Since two patients told that they did not receive any treatment and the rest was unknown, pharmacologic agents were not considered and not included in statistics in this study. The only one subject in Test Group who lost one implant was using calcium, vitamin $\mathrm{D}$ and denosumab which is a human monoclonal antibody. Although denosumab has been reported to be associated with ONJ, [26] the association of this new therapy is unclear so it is questionable to attribute the only detected failure to the medication used by the patient. Perhaps this failure might be due to the type of prosthetic superstructure since higher implant failure for overdentures, that are generally preferred in complex cases, was reported [36].

One of the limitations of this study was that all subjects were not diagnosed as osteoporosis; a larger number of patients with osteoporosis rather than osteopenia would be beneficial. Seventeen of the subjects were diagnosed as osteoporosis and nine of them were diagnosed as osteopenia according to their T-scores. Since T-scores of the subjects did not show normal distributions, the data for this parameter was presented as means and SDs of means, and median values with minimum/maximum. While mean value was $-2,55 \pm 0,53$; minimum and maximum values were $-1,20$ and $-3,40$, respectively. Information about the duration of being diagnosed as osteoporosis/osteopenia is unfortunately not enough. We only know the duration of 15 subjects and the rest is unknown. The average duration of being osteoporosis/ osteopenia for these patients is 10 years. Another limitation was the lack of knowledge about the medications used by the subjects. Pharmacologic agents, that are often prescribed in osteoporotic patients, may have an effect on the peri-implant bone. Since we could not obtain sufficient information about the medications, pharmacologic agents were not considered.

\section{Conclusion}

The main goal of this study was to determine if dental implants were a safely preferable treatment choice for patients with osteoporosis/osteopenia. The present study shows that PO and reduced BMD does not affect long-term success of implants. Based on the results of this study and alongside with recent studies, it can be concluded that dental implant therapy is a preferable option and a diagnosis of osteoporosis/osteopenia is not a contraindication in these patients.

Out the duration of being diagnosed as osteoporosis/osteopenia is unfortunately not enough. We only know the duration of 15 subjects and the rest is unknown. The average duration of being osteoporosis/osteopenia for these patients is 10 years. Another limitation was the lack of knowledge about the medications used by the subjects. Pharmacologic agents, that are often prescribed in osteoporotic patients, may have an effect on the peri-implant bone. Since we could not obtain sufficient information about the medications, pharmacologic agents were not considered.

\section{Declarations}

\section{Ethics approval and consent to participate}

The authors certify that they have obtained all appropriate patient consent forms. In the form the patient(s) has/have given his/ her/their consent for his/her/their images and other clinical information to be reported in the journal. The patients understand that their names and initials will not be published and due efforts will be made to conceal their identity, but anonymity cannot be guaranteed. Ethical approval was obtained from the ethics committee at the Ministry of Higher Education in Syria. Written informed consent was obtained from each participant in this study.

\section{Competing interests}

The authors declare that they have no competing interests

\section{Funding}

The study was self- funded.

\section{Authors' contributions}

Wasim alsadi conducted the study in damascus, analyzed the results wrote a report on the survey, sent them to Haya al jabban, 
who drafted this manuscript and corrected and revised the final version.

\section{Acknowledgements}

The authors express their appreciation to Damascus university faculty of dentistry, that facilitated this research. And to the department of periodontology.

\section{Availability of data and materials}

Once published, the data and material in this paper can be obtained from the authors.

\section{Consent for publication}

As mentioned above, all the authors have read and approved the final version of this manuscript. No clinical images or details of the participated are included in the manuscript and their anonymity has been preserved.

\section{References}

[1]. Adell R, Eriksson B, Lekholm U, Brånemark PI, Jemt T. Long-term followup study of osseointegrated implants in the treatment of totally edentulous jaws. Int J Oral Maxillofac Implants. 1990 Winter;5(4):347-59. Pubmed PMID: 2094653.

[2]. Allen B, Migliorati C, Rowland C, An Q, Shintaku W, Donaldson M, Wells M, Kaste S. Comparison of mandibular cortical thickness and QCT-derived bone mineral density (BMD) in survivors of childhood acute lymphoblastic leukemia: a retrospective study. Int J Paediatr Dent. 2016 Sep;26(5):330-5. Epub 2015 Sep 15. Pubmed PMID: 26370921.

[3]. Alqutaibi AY, Radi IA. No Clear Evidence Regarding the Effect of Osteoporosis on Dental Implant Failure. J Evid Based Dent Pract. 2016 Jun;16(2):1246. 2016.06.002. Epub 2016 Jun 4. Pubmed PMID: 27449843.

[4]. Ayed MS, Alsharif AF, Divakar DD, Jhugroo C, Alosaimi B, Mustafa M. Evaluating the possible association between systemic osteoporosis and periodontal disease progression in postmenopausal women. Dis Mon. 2019 Jun;65(6):193-215. Pubmed PMID: 30502098.

[5]. Barbu HM, Comaneanu RM, Andreescu CF, Mijiritsky E, Nita T, Lorean A. Dental Implant Placement in Patients With Osteoporosis. J Craniofac Surg. 2015 Sep;26(6):e558-9. Pubmed PMID: 26355991.

[6]. Berardini M, Trisi P, Sinjari B, Rutjes AW, Caputi S. The Effects of High Insertion Torque Versus Low Insertion Torque on Marginal Bone Resorption and Implant Failure Rates: A Systematic Review With Meta-Analyses. Implant Dent. 2016 Aug;25(4):532-40. Pubmed PMID: 27129002.

[7]. Boyanov M, Shinkov A, Psachoulia E, Intorcia M, Petkova R. Baseline Characteristics and Changes in Bone Mineral Density T-Scores of Bulgarian Women with Postmenopausal Osteoporosis Receiving Denosumab in Routine Clinical Practice. Drugs R D. 2017 Mar;17(1):125-132. Pubmed PMID: 27988913.

[8]. Cai S, Yu H, Li Y, He X, Yan L, Huang X, Wang P. Bone mineral density measurement combined with vertebral fracture assessment increases diagnosis of osteoporosis in postmenopausal women. Skeletal Radiol. 2020 Feb;49(2):273-280. Pubmed PMID: 31352490.

[9]. Choi MH, Lee K, Kim MY, Shin HI, Jeong D. Pisidium coreanum Inhibits Multinucleated Osteoclast Formation and Prevents Estrogen-Deficient Osteoporosis. Int J Mol Sci. 2019 Dec 2;20(23):6076. Pubmed PMID: 31810213

[10]. Chow L, Chow TW, Chai J, Mattheos N. Bone stability around implants in elderly patients with reduced bone mineral density - a prospective study on mandibular overdentures. Clin Oral Implants Res. 2017 Aug;28(8):966973. Epub 2016 Jun 29. Pubmed PMID: 27357723.

[11]. Cosman F. Osteoporosis options. Choose medication based on age, health, and family history. Health News. 2003 Jul;9(7):3.Pubmed PMID: 12838920

[12]. Dvorak G, Arnhart C, Heuberer S, Huber CD, Watzek G, Gruber R. Periimplantitis and late implant failures in postmenopausal women: a crosssectional study. J Clin Periodontol. 2011 Oct;38(10):950-5. Epub 2011 Jul 21.Pubmed PMID: 21777269

[13]. Famili P, Zavoral JM. Low Skeletal Bone Mineral Density Does Not Affect
Dental Implants. J Oral Implantol. 2015 Oct;41(5):550-3. Epub 2014 Jun 19. Pubmed PMID: 24945991.

[14]. G Giro G, Chambrone L, Goldstein A, Rodrigues JA, Zenóbio E, Feres M, Figueiredo LC, Cassoni A, Shibli JA. Impact of osteoporosis in dental implants: A systematic review. World J Orthop. 2015 Mar 18;6(2):311-5. Pubmed PMID: 25793172.

[15]. Gosch M, Bail HJ, Grueninger S, Stumpf U, Kammerlander C, Wicklein $S$. What is a reasonable rate for specific osteoporosis drug therapy in older fragility fracture patients? Arch Osteoporos. 2020 Feb 22;15(1):20.Pubmed PMID: 32088765 .

[16]. Grisa A, Veitz-Keenan A. Is osteoporosis a risk factor for implant survival or failure? Evid Based Dent. 2018 Jun;19(2):51-52. Pubmed PMID: 29930358.

[17]. Hamada M, Kajita E, Tamaki J, Kouda K, Sato Y, Tachiki T, Yura A, Kamiya K, Nitta A, Kagamimori S, Iki M. Decreased bone mineral density and osteoporotic fractures are associated with the development of echogenic plaques in the carotid arteries over a 10-year follow-up period: The Japanese Population-based Osteoporosis (JPOS) Cohort Study. Maturitas. 2020 Jan;131:40-47. Pubmed PMID: 31787146.

[18]. Holahan CM, Koka S, Kennel KA, Weaver AL, Assad DA, Regennitter FJ, Kademani D. Effect of osteoporotic status on the survival of titanium dental implants. Int J Oral Maxillofac Implants. 2008 Sep-Oct;23(5):905-10. Pubmed PMID: 19014161.

[19]. Hulshof FFB, Papenburg B, Vasilevich A, Hulsman M, Zhao Y, Levers M, Fekete N, de Boer M, Yuan H, Singh S, Beijer N, Bray MA, Logan DJ, Reinders M, Carpenter AE, van Blitterswijk C, Stamatialis D, de Boer J. Mining for osteogenic surface topographies: In silico design to in vivo osseointegration. Biomaterials. 2017 Aug;137:49-60. Epub 2017 May 12. Pubmed PMID: 28535442.

[20]. Jaghsi S, Hammoud T, Haddad S. Relation Between Circulating Vitamin K1 and Osteoporosis in the Lumbar Spine in Syrian Post-Menopausal Women. Open Rheumatol J. 2018 Jan 22;12:1-9. Pubmed PMID: 29541269.

[21]. Janiszewska M, Firlej E, Dziedzic M, Żołnierczuk-Kieliszek D. Health beliefs and sense of one's own efficacy and prophylaxis of osteoporosis in periand post-menopausal women. Ann Agric Environ Med. 2016;23(1):167-73. Pubmed PMID: 27007538.

[22]. Korn P, Kramer I, Schlottig F, Tödtman N, Eckelt U, Bürki A, Ferguson SJ, Kautz A, Schnabelrauch M, Range U, Kneissel M, Stadlinger B. Systemic sclerostin antibody treatment increases osseointegration and biomechanical competence of zoledronic-acid-coated dental implants in a rat osteoporosis model. Eur Cell Mater. 2019 May 17;37:333-346. Pubmed PMID: 31112281.

[23]. Kozlova MV, Mkrtumyan AM, Bazikyan EA, Belyakova AS, Dzikovitskaya LS. Otsenka éffektivnosti primeneniia dental'nykh implantatov $s$ konditsionirovanno $\bigotimes$ poverkhnost'iu na osnove gidroksida natriia u patsientov $s$ osteoporozom [Effect of dental implants with conditioned surface based on sodium hydroxide in patients with osteoporosis]. Stomatologiia (Mosk). 2019;98(3):46-51. Russian. Pubmed PMID: 31322594.

[24]. Langdahl BL. Overview of treatment approaches to osteoporosis. Br J Pharmacol. 2021 May;178(9):1891-1906. Pubmed PMID: 32060897.

[25]. Lotz EM, Cohen DJ, Ellis RA, Wayne JS, Schwartz Z, Boyan BD. Ibandronate Treatment Before and After Implant Insertion Impairs Osseointegration in Aged Rats with Ovariectomy Induced Osteoporosis. JBMR Plus. 2019 Mar 6;3(7):e10184. Pubmed PMID: 31372590.

[26]. Matsuo A, Hamada H, Takahashi H, Okamoto A, Kaise H, Chikazu D. Evaluation of dental implants as a risk factor for the development of bisphosphonate-related osteonecrosis of the jaw in breast cancer patients. Odontology. 2016 Sep;104(3):363-71. Epub 2015 May 9. Pubmed PMID: 25956267.

[27]. Nguyen VH. Smoking Status on Bone Health and Osteoporosis Prevalence. Osong Public Health Res Perspect. 2018 Aug;9(4):213-214. Pubmed PMID: 30159228.

[28]. Poxleitner P, Steybe D, Kroneberg P, Ermer MA, Yalcin-Ülker GM, Schmelzeisen R, Voss PJ. Tooth extractions in patients under antiresorptive therapy for osteoporosis: Primary closure of the extraction socket with a mucoperiosteal flap versus application of platelet-rich fibrin for the prevention of antiresorptive agent-related osteonecrosis of the jaw. J Craniomaxillofac Surg. 2020 Apr;48(4):444-451.Epub 2020 Feb 18. Pubmed PMID: 32122726.

[29]. Richa, R Y, Puranik MP, Shrivastava A. Association between osteoporosis and periodontal disease among postmenopausal Indian women. J Investig Clin Dent. 2017 Aug;8(3). Pubmed PMID: 27339765.

[30]. Roos J, Sennerby L, Lekholm U, Jemt T, Gröndahl K, Albrektsson T. A qualitative and quantitative method for evaluating implant success: a 5-year retrospective analysis of the Brånemark implant. Int J Oral Maxillofac Implants. 1997 Jul-Aug;12(4):504-14. Pubmed PMID: 9274079.

[31]. Sadat-Ali M, Al-Dakheel DA, Azam MQ, Al-Bluwi MT, Al-Farhan MF, 
AlAmer HA, Al-Meer Z, Al-Mohimeed A, Tabash IK, Karry MO, Rassasy YM, Baragaba MA, Amer AS, AlJawder A, Al-Bouri KM, ElTinay M, Badawi HA, Al-Othman AA, Tayara BK, Al-Faraidy MH, Amin AH. Reassessment of osteoporosis-related femoral fractures and economic burden in Saudi Arabia. Arch Osteoporos. 2015;10:37. Epub 2015 Oct 22. Pubmed PMID: 26494131.

[32]. Schwartz-Arad D, Herzberg R, Levin L. Evaluation of long-term implant success. J Periodontol. 2005 Oct;76(10):1623-8. Pubmed PMID: 16253082.

[33]. Siebert T, Jurkovic R, Statelova D, Strecha J. Immediate Implant Placement in a Patient With Osteoporosis Undergoing Bisphosphonate Therapy: 1-Year Preliminary Prospective Study. J Oral Implantol. 2015 Jul;41 Spec No:3605. Pubmed PMID: 24041299.

[34]. Solimeo SL, Nguyen VT, Edmonds SW, Lou Y, Roblin DW, Saag KG, Cram P, Wolinsky FD. Sex differences in osteoporosis self-efficacy among community-residing older adults presenting for DXA. Osteoporos Int. 2019 May;30(5):1033-1041. Epub 2019 Jan 30.Pubmed PMID: 30701343.

[35]. SONG, Y. L. 2010. [Implant osseointegration with osteoporosis]. Zhonghua Kou Qiang Yi Xue Za Zhi, 45, 734-7.

[36]. Stavropoulos A, Bertl K, Pietschmann P, Pandis N, Schiødt M, Klinge B. The effect of antiresorptive drugs on implant therapy: Systematic review and meta-analysis. Clin Oral Implants Res. 2018 Oct;29 Suppl 18:54-92. Pubmed PMID: 30306695.

[37]. K Giri T, Newton D, Chaudhary O, Deych E, Napoli N, Villareal R, Diemer
K, E Milligan P, F Gage B. Maximal dose-response of vitamin-K2 (menaquinone-4) on undercarboxylated osteocalcin in women with osteoporosis. Int J Vitam Nutr Res. 2020 Jan;90(1-2):42-48. Epub 2019 Feb 28. Pubmed PMID: 30816822.

[38]. Taguchi A, Shiraki M, Tanaka S, Ohshige H, Nakamura T. Improved periodontal disease and prevention of tooth loss in osteoporosis patients receiving once-yearly zoledronic acid: a randomized clinical trial. Menopause. 2019 Nov;26(11):1277-1283. Pubmed PMID: 31688575.

[39]. Temmerman A, Keestra JA, Coucke W, Teughels W, Quirynen M. The outcome of oral implants placed in bone with limited bucco-oral dimensions: a 3-year follow-up study. J Clin Periodontol. 2015 Mar;42(3):311-8. Pubmed PMID: 25682801

[40]. Walker J. Osteoporosis and fragility fractures: risk assessment, management and prevention. Nurs Older People. 2020 Jan 28;32(1):34-41. Epub 2019 Dec 12. Pubmed PMID: 31854161.

[41]. Hildebolt CF. Osteoporosis and oral bone loss. Dentomaxillofac Radiol. 1997 Jan;26(1):3-15. Pubmed PMID: 9446984.

[42]. Misch CE, Perel ML, Wang HL, Sammartino G, Galindo-Moreno P, Trisi P, Steigmann M, Rebaudi A, Palti A, Pikos MA, Schwartz-Arad D, Choukroun J, Gutierrez-Perez JL, Marenzi G, Valavanis DK. Implant success, survival, and failure: the International Congress of Oral Implantologists (ICOI) Pisa Consensus Conference. Implant Dent. 2008 Mar;17(1):5-15. Pubmed PMID: 18332753. 